\title{
Teleducation about Cleft Lip and Palate: An Interdisciplinary Approach in the Promotion of Health
}

\author{
Camila de Castro Corrêa ${ }^{1}$ Thais Freire ${ }^{1}$ Júlia Speranza Zabeu ${ }^{1}$ Aline Martins $^{1}$ Rafael Ferreira ${ }^{2}$ \\ Paulo Afonso Silveira Francisconi ${ }^{3}$ Jeniffer de Cássia Rillo Dutka ${ }^{1}$ Wanderléia Quinhoeiro Blasca ${ }^{1}$
}

${ }^{1}$ Department of Speech-Language Pathology and Audiology,

Address for correspondence Camila Corrêa, BS, MSc, Department of Universidade de São Paulo, Bauru School of Dentistry, Bauru, Sao Paulo, Brazil

2 Department of Prosthesis, Universidade de São Paulo, Bauru School of Dentistry, Bauru, São Paulo, Brazil

${ }^{3}$ Department of Operative Dentistry, Universidade de São Paulo, Bauru School of Dentistry, Bauru, São Paulo, Brazil Speech-Language Pathology and Audiology, University of São Paulo, Bauru School of Dentistry, Octávio Pinheiro Brisola Street, Bauru, Sao Paulo 17012-901, Brazil (e-mail: camila.ccorrea@hotmail.com; camilacorrea@usp.br).

Int Arch Otorhinolaryngol 2015;19:106-111.

\begin{abstract}
Keywords

- cleft palate

- speech, language, and hearing sciences

- dentistry

- health education

- telehealth

Introduction The Young Doctor Project (YDP) uses Telehealth and Interactive Teleducation instruments to promote the integration of different areas of health and to build knowledge. This methodology can also foster public awareness on various issues related to health. In this context, the objective of this study was to emphasize cleft lip and palate (CLP), which is one of the most common birth defects in Brazil.

Objective The study aimed to apply a model of education regarding CLP, based on the dynamics of the YDP, and to evaluate the participants' knowledge acquired after participating in the YDP.

Methods The participants were 41 students, 13 to 15 years of age and at the eightand ninth-grade levels in a private elementary school in Bauru (Brazil). To analyze the performance of the participants, a questionnaire was administered before and after the completion of the training program. The training program was structured in three steps using: (1) interactive teleducation classes, (2) a cybertutor, and (3) practical activities. Results There was a statistically significant difference between the pre- and postparticipation questionnaire results. The improved performance of participants is evidenced by the increase in the rate of correct answers on all issues.

Conclusion The YDP on CLP was applied in the school setting following the three steps recommended by the project, and, after the implementation of the training program, there was a significant increase in participants' knowledge of CLP. The YDP on CLP proved an effective tool in promoting health education.
\end{abstract}

\section{Introduction}

In Brazil, data suggest that there are $\sim 260,000$ individuals with cleft lip and palate (CLP). This is the third or fourth most common birth defect in the country. People with CLP and craniofacial deformities may have functional disorders that impair eating, speech, and dental-occlusal relationships. ${ }^{1,2}$ Craniofacial malformations may be associated with physical disfiguration and communication disorders, which may harm the social lives of individuals who are afflicted by them. There received

August 2, 2014

accepted

December 14, 2014

published online

January 19, 2015
DOI http://dx.doi.org/

10.1055/s-0034-1544114. ISSN 1809-9777.
Copyright (c) 2015 by Thieme Publicações License terms

Ltda, Rio de Janeiro, Brazil
(®) $\Theta \circledast$ 
is a high frequency of isolation, social discrimination, and bullying in this population. ${ }^{3}$ It is the role of health professionals to promote health education that improves interpersonal relationships and facilitates social inclusion of individuals with impairment related to malformation into society. 4

Health education can be understood as a social practice that enables critical and transformative reflection and behavioral change as well as promotes the welfare of patients. ${ }^{4}$ Besides traditional methodologies in education, information and communication technologies can be used to disseminate health knowledge, especially regarding the promotion of positive attitudes toward health. ${ }^{5}$ The Young Doctor Project (YDP), therefore, is an initiative that involves the use of interactive teleducation, integrating the areas of health and education, to promote classroom experiences that foster knowledge construction and exchange among elementary, middle, and high school students. ${ }^{6,7}$ The YDP is an excellent teaching methodology that enables health education promoting awareness of the role of each person as an active health agent in the community. ${ }^{8}$ The project started in 2007 and since then has been used across the country in different regions and sectors, establishing a link between students of elementary, middle, and high school and teachers. ${ }^{9,10}$

When used within the area of speech-language pathology and audiology, the YDP has addressed topics related to hearing and vocal health using various venues to convey information and exchange knowledge including activities within the classroom, cybertutors, and use of software such as "Virtual Man" to promote integration of knowledge and motivate involvement. ${ }^{11,12}$ Other YDPs have addressed the topic of genetic syndromes ${ }^{13}$ as well as oral health. ${ }^{14}$

The current YDP addressed the topic of CLP integrating the areas of speech-language pathology, audiology, and dentistry, aiming to improve public awareness regarding one of the most common birth defects. To accomplish the task of health promotion, this study had two objectives: to develop and implement a health education strategy based on the dynamic methodology of the YDP while addressing the topic of CLP and to evaluate the performance of school-aged children regarding the acquisition of knowledge about CLP after attending the YDP.

\section{Materials and Methods}

\section{Ethical Aspects}

The study was approved by the Ethics Committees of the institution involved in the YDP. To conduct this project, partnerships were established between two universities, one hospital specialized in the management of CLP and a private elementary-middle school.

\section{Participants}

All 50 middle school students from eighth- and ninth-grade levels were invited to participate in this study. Because not all students had access to the Internet outside the school environment, the project was conducted at the school informatics laboratory. The sample was limited to 50 students because there were 25 computers with Internet access available, and the students accessed the cybertutor in pairs at a time suitable to all. Only students who signed the informed consent form together with their parents were included. To select a site to conduct the project, the researchers identified a school that had students with CLP attending regular classes and also identified teachers and administrative staff interested in the project. The participating school fit the criteria and participated as the site for this project.

\section{Procedures}

After identifying the school and the students, the participants underwent the YDP's (http://www.projetojovemdoutor.org. $\mathrm{br} /$ ) training program, which is structured in three steps.

\section{Step 1-Lectures about the Topic of Interest}

At the first meeting, the participants attended a lecture given by the researchers, which lasted 2 hours. The class was held at the university responsible for this study and addressed topics related to CLP: predisposition to bullying and discrimination, definition, classification, embryology, etiology, diagnostics, team treatment, family structure and support, and speechlanguage pathology, audiology, and dental aspects of CLP management. A PowerPoint (Microsoft Corp., Redmond, Washington, United States) presentation including illustrations and videos was prepared and used during the first class.

\section{Step 2-Cybertutor}

Each participant received a login ID and password to access an online classroom on the YDP Web site (cybertutor). The interactive teleducation was meant to facilitate the completion by the students. Participants were able to control their own learning, accessing the cybertutor freely and establishing their own study schedules, within the period assigned for review of the material. The interactive classroom allowed collaboration between the users through mailing lists and forums to clarify doubts about the content available on cybertutor. The cybertutor development involved a partnership between the two universities engaged in this study.

The topics addressed in the cybertutor regarding CLP included definition, embryology (how and when CLP occurs during pregnancy), etiology, diagnostics, treatment, first caregiver concerns, and first care for babies with CLP, along with presentation of psychosocial issues related to bullying and prejudice associated with CLP. After completion of the introductory content on CLP, more specific information about speech-language pathology, audiology, and dental aspects related to the management of CLP were made available through the cybertutor.

\section{Step 3-Sharing the Knowledge Gained (Practical Activities)}

At step 3, the participants were quizzed regarding the topics presented during the lecture and with the cybertutor. Students were divided into five groups to take the quiz involving group interactions. The group that had the highest number of correct answers was encouraged to explain those topics of mastery to the other groups. The participants were than 
acknowledged by the team of researchers who advised them during the process along with their teachers as "young doctors." They were also guided to organize social activities aimed at disseminating the knowledge gained during the YDP. A chart demonstrating the sequence of steps taken during the process for the students to become young doctors in the topic of CLP is presented in - Fig. 1.

\section{Assessment Tool}

To analyze the learning of the participants, they were administered questionnaires before and after completion of the YDP. The questionnaire for the assessment of student performance consisted of two essay questions (questions 1 and 13) and 11 multiple-choice questions (questions 2 through 12). The questionnaire was developed by the research team and reviewed by professionals from the hospital specializing in the management of CLP. The essay questions addressed general knowledge of the students about CLP (question 1: What do you know about the cleft lip and palate?) and also investigated the students' opinion regarding differences between individuals with and without cleft (question 13: Are there differences between individuals with and without cleft? If yes, describe). To determine the participants' performance in the essay questions, the researchers searched for three main responses. The researchers expected to read answers that CLP is present at birth (congenital anomaly); that the cleft is an opening that can affect the lip and/or palate, changing the face and mouth; and that the presence of CLP does not involve cognitive problems that can affect intellectual abilities. If the participant included at least two of these three responses, the reply to the essay questions was considered correct. The multiple-choice questions addressed the content included in the cybertutor, with one correct answer among five possibilities. The findings were analyzed statistically using the Student paired-samples $t$ test, adopting a significance level of $5 \%$.

\section{Results}

\section{Participants}

After inviting all 50 students from eighth- and ninth-grade levels, 41 accepted and signed the informed consent forms along with their parents. Nine students (18\%) did not accept the invitation, indicating that they were not interested in the project. The participants were 16 (39\%) boys and 25 (61\%) girls with ages between 13 and 15 years (mean: 13 years).

\section{Procedures}

\section{Step 1-Lectures about the Topic of Interest}

Before the initial lecture with the participants, the questionnaires to evaluate the knowledge of the 41 participants on issues regarding CLP were applied for baseline data. The participants attended the lecture and the interaction with the researchers to discuss the content presented about CLP. During the lecture, before discussing the information, the opinion of the students was frequently asked and they were invited to reflect about the content provided. During the interactions, the researchers identified the overall level of knowledge of the group about CLP. It was noted that the involvement of the participants was enthusiastic, as they remained attentive and asked questions during the lecture.

The interaction between researchers and students was the venue for introduction of information about CLP. The content addressed during the three steps of the YDP included: definition, terminology comprising technical terms related to management of CLP, possible disorders and consequences related to malformations, and treatment options. The information provided in this first meeting was essential to enable the students to understand the issues addressed in the step 2 with the cybertutor. Therefore, the material provided in the initial lecture was designed to foster the learning intended at the end of the project.

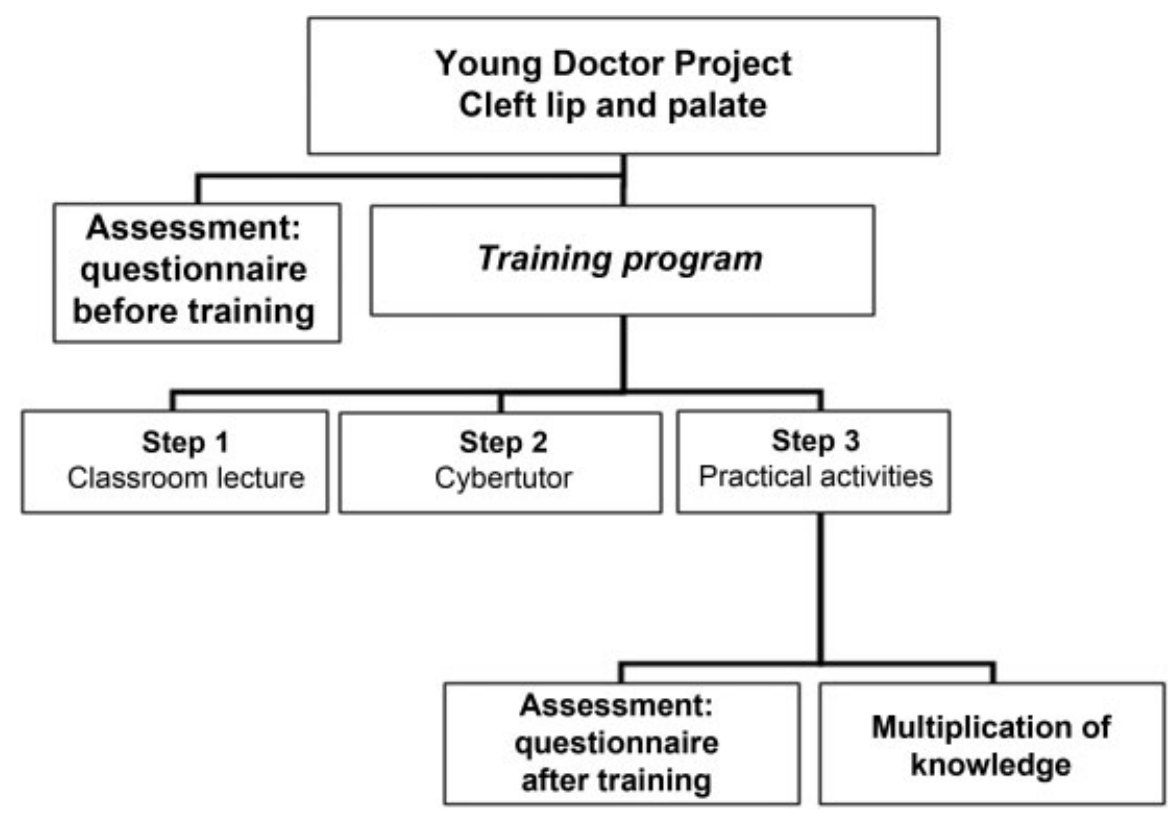

Fig. 1 Organizational chart of procedures performed during the Young Doctor Project in cleft lip and palate. 


\section{Step 2-Cybertutor}

After the initial lecture, the students were told that they had 1 month to access the material presented with the cybertutor. The majority of the students (87.80\%) accessed all of the subjects in cybertutor and $75.60 \%$ accessed the two additional forums that were available. The forums promoted interactions between participants and researchers and allowed the clarification of doubts about the content in the cybertutor.

\section{Step 3-Sharing the Knowledge Gained (Practical}

\section{Activities)}

The students were asked to share and expand the knowledge gained in steps 1 and 3 during interactions in a group quiz activity. During the quiz, some questions/doubts regarding the content addressed in the initial lecture and the cybertutor were resolved (-Fig. 2). To solve these questions, the researchers asked the help of the participating students to clarify the doubts of their colleagues.

Students, teachers, and researchers organized pamphlets, plays, games, workshops, and lectures about CLP to share and display within the school environment (-Fig. 3). These social actions enabled the young doctors to disseminate knowledge to other students in their schools, family, and community.

\section{Data Analysis}

To assess the knowledge retained by the participants, they were presented with questionnaires before and after the YDP. - Table 1 presents the overall scores for the 41 participants for the 13 questions with the corresponding amount $(n)$ and percentage (\%) of correct answers. The questionnaires before the YDP revealed that 9 (69\%) of the 13 questions were answered with less than $75 \%$ accuracy by 41 students (questions $1,3,4,6,7,8,9,10$, and 12) and that 4 of these 9 questions were answered with less than $50 \%$ accuracy. The highest rates of correct answers were observed for the content addressing classification, diagnostics, and differences between individuals with and without CLP (questions 2, 5, 11, and 13). Question 11 already was answered with $100 \%$ correct answers before YDP.

- Table 1 also presents the overall scores obtained on the questionnaire after the YDP. The number of correct answers increased for all questions except question 11 . The differences between the before and after YDP conditions revealed an improvement in correct answers that ranged between 4.8 and 88.8\%. Inferential statistical comparison of mean correct answers before and after the YDP revealed a statistically significant difference between the two conditions $(p=0.001, t=6.687)$.

\section{Discussion}

Interactive teleducation involves the optimization of technological and educational resources for the purpose of stimulating interactivity, promoting self-directed learning, and maintaining student interest and motivation. ${ }^{13,14}$ Maintaining student interest during educational activities in particular may foster learning and knowledge retention. ${ }^{6,8,12}$ A previous study suggested that the development of health-education programs should be encouraged by educational practices, especially those that involve interactive teleducation. ${ }^{4}$

The results of the YDP about CLP corroborate the findings of previous studies, $4,6,8,12-14$ revealing an increase in students' knowledge after participating in a learning program involving interactive teleducation. A statistically significant difference between the number of correct answers before and after the YDP suggested that the interactive educational strategies employed in this study aided the learning process. The YDP was shown to be an effective tool to disseminate information and to increase participants' knowledge. Because the entire school community was involved in the social activities at step 3, a spreading effect is also expected, resulting in promotion of health education regarding information and attitudes regarding persons with CLP.

The questions that addressed definition (question 1), embryology (question 3), etiology (question 4), and treatment (question 8) of CLP showed the lowest rates of correct answers before the YDP. After the program, the correct answers for these questions increased $\sim 50 \%$ overall. Question 3 showed one of the lowest increase rates after YDP. These findings can be explained due to the difficulty of the assimilation of content related to embryologic information at the middle school level, because this content is generally addressed with students at the high school level in Brazil. ${ }^{15}$ The results for question 1 are noteworthy. This question showed the lowest rate of correct answers before the YDP (9.8\%). After

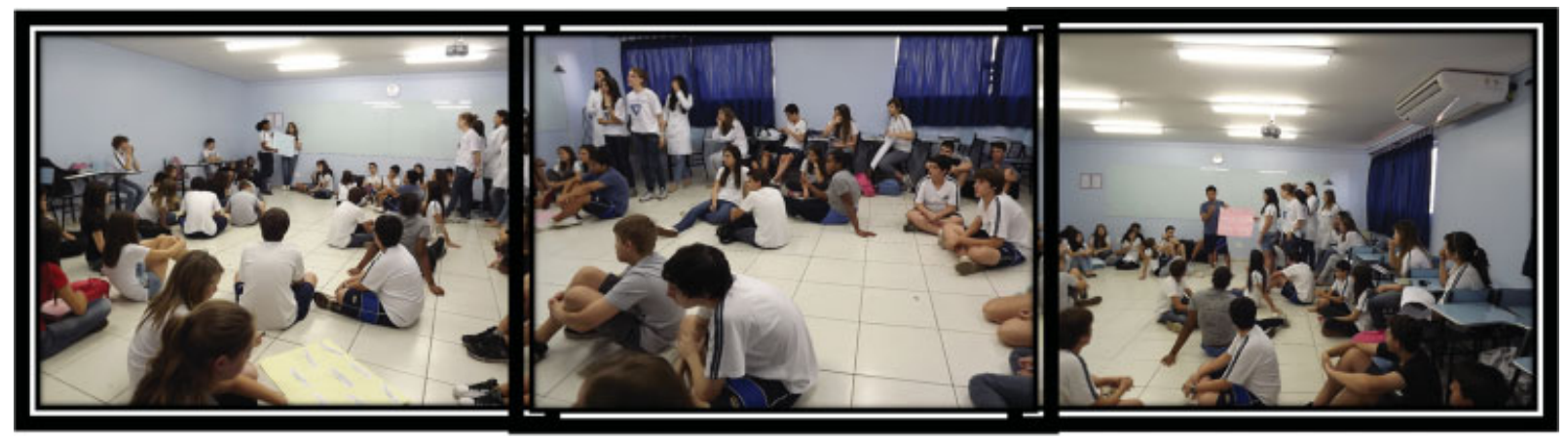

Fig. 2 Practical activity: group quiz. 


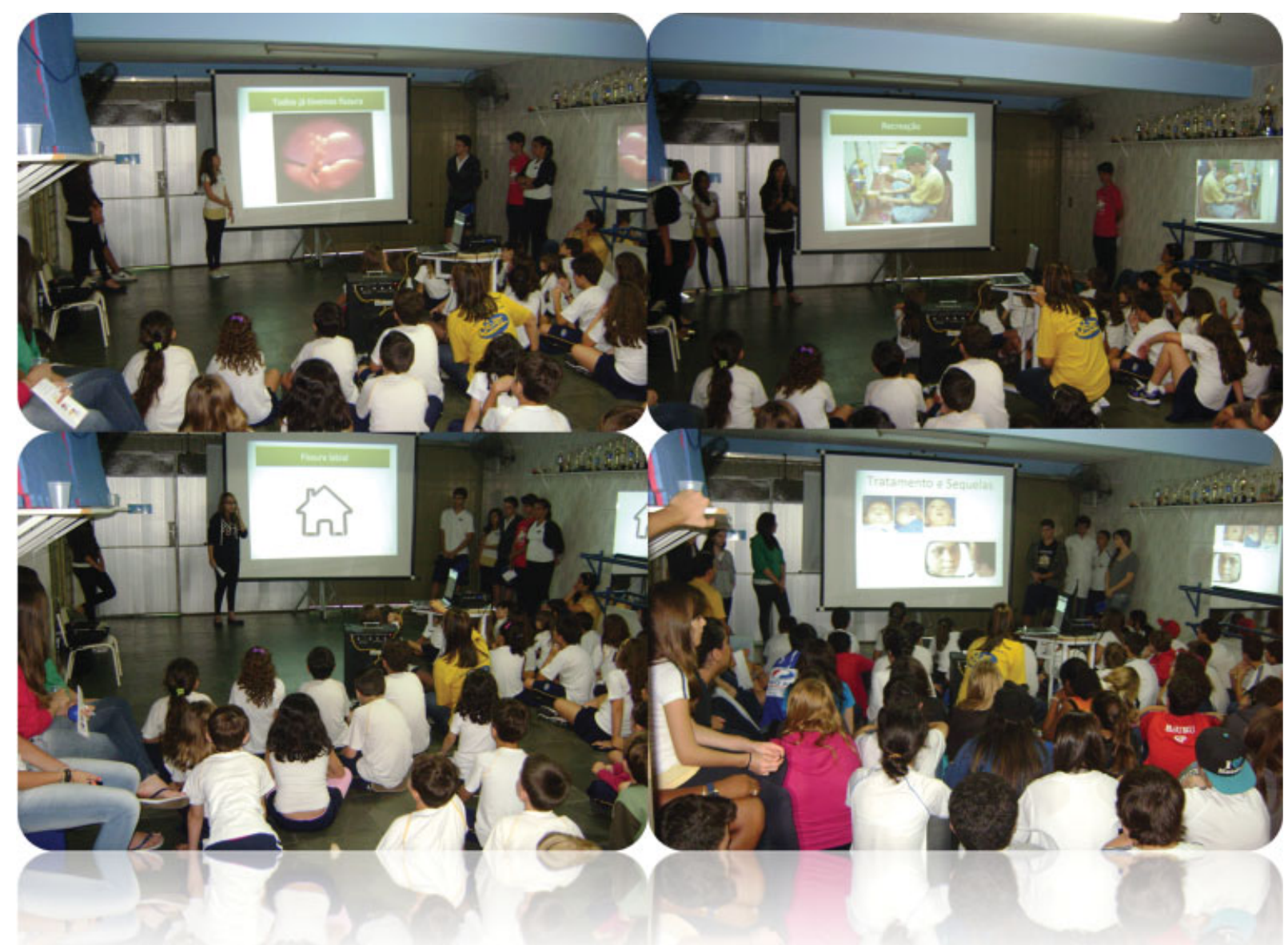

Fig. 3 Practical activity: disseminating knowledge.

the program, the rate of correct answers obtained was $97.6 \%$, with nearly $100 \%$ of the participants showing that they achieved a better understanding about CLP.

The YDP was developed within the school environment involving direct and indirect participation of the school community. Including teachers and staff in health education initiatives like the YDP can optimize efforts to build healthy environments and to change attitudes of the community regarding bullying and discrimination. ${ }^{16}$ Although the objective of this project was to measure the knowledge gained by the participants, it is the opinion of the authors that health promotion actions like the ones proposed within the YDPs can lead to cooperation and collaboration, easing the teaching of complex topics, such as CLP, while fostering supportive environments that promote inclusion of children with differences in the mainstream school system. This is exactly the scope of the YDP. To the participants, becoming a young doctor allows the students to take a role in health promotion and advocacy once they are trained to disseminate specific knowledge in a given community. ${ }^{6}$

In this project, the young doctors acted as multipliers of knowledge, transmitting information to other school students, teachers, staff, relatives, and their community through social action. It is not possible to measure the exact number of people who received the information. Even so, this project has the combined health and education elements that allow for dissemination of information needed to change behavior regarding inclusion of persons with malformations in society. At the same time, the experience helps to promote the idea of a productive health chain.

Previous studies also revealed that the YDP can be effective in promoting knowledge acquisition but also suggested that it is an important tool to generate behavioral changes, particularly related to attitudes of the participants toward social inclusion of individuals with differences or disabilities. ${ }^{6,13}$ Question 12 approached the aspect of inclusion in this study. Before the YDP, 39\% of the participants were unfavorable to inclusion initiatives, and after the YDP, only 7.3\% participants still disapproved inclusion of people with differences related to CLP. The use of technology in educational programs such as the cybertutor, for example, supports self-directed learning, allowing the participant to build knowledge before engaging in interactions within a group. When these educational strategies are combined with activities involving interactions that require the practical use of the information exchanged, the potential to increase knowledge and to promote behavioral change can be optimized and broadened. ${ }^{13}$

The YDP on CLP, as reported in this study, showed changes in the participant's attitudes toward inclusion. Similar health education projects should be encouraged, because they can maximize dissemination of knowledge at the same time that they promote engagement of participants with their own health and the overall health of their communities. ${ }^{5,6,17}$ 
Table 1 Questionnaire results before and after the YDP

\begin{tabular}{|c|c|c|c|c|c|c|c|}
\hline \multirow[t]{2}{*}{ Questions } & \multirow[t]{2}{*}{ Topics related to CLP } & \multicolumn{2}{|c|}{$\begin{array}{l}\text { Correct answers } \\
\text { before YDP }\end{array}$} & \multicolumn{2}{|c|}{$\begin{array}{l}\text { Correct answers } \\
\text { after YDP }\end{array}$} & \multicolumn{2}{|c|}{$\begin{array}{l}\text { Improvement after } \\
\text { YDP }\end{array}$} \\
\hline & & $\%$ & $n$ & $\%$ & $n$ & $\%$ & $n$ \\
\hline 1 & Definition & 9.8 & 4 & 97.6 & 40 & 88.8 & 36 \\
\hline 2 & Classification & 85.4 & 35 & 100 & 41 & 14.6 & 6 \\
\hline 3 & Embryology & 22 & 9 & 26.8 & 11 & 4.8 & 2 \\
\hline 4 & Etiology & 26.8 & 11 & 65.9 & 27 & 39 & 16 \\
\hline 5 & Diagnostics & 78 & 32 & 97.6 & 40 & 19.5 & 8 \\
\hline 6 & Alterations & 68.3 & 28 & 100 & 41 & 31.7 & 13 \\
\hline 7 & Treatment & 51.2 & 21 & 73.2 & 30 & 21.9 & 9 \\
\hline 8 & Treatment & 34.1 & 14 & 80.5 & 33 & 46.3 & 19 \\
\hline 9 & Disorders & 73.2 & 30 & 82.9 & 34 & 9.7 & 4 \\
\hline 10 & Treatment & 56.1 & 23 & 65.9 & 27 & 9.7 & 4 \\
\hline 11 & Social attitudes & 100 & 41 & 100 & 41 & 0 & 0 \\
\hline 12 & Social attitudes & 61 & 25 & 92.7 & 38 & 31.7 & 13 \\
\hline 13 & Cleft features & 95.1 & 39 & 100 & 41 & 4.8 & 2 \\
\hline Mean & & 58.5 & 24 & 83.3 & 34.1 & 24.8 & $10.1^{a}$ \\
\hline Minimum & & 9.2 & 4 & 26 & 11 & 16.8 & 7 \\
\hline Maximum & & 100 & 41 & 100 & 41 & 0 & 0 \\
\hline
\end{tabular}

Abbreviations: CLP, cleft lip and palate; YDP, Young Doctor Project.

${ }^{\mathrm{a}}$ The difference between the means before and after training was statistically significant according to the paired Student $t$ test $(t=6.687, p=0.001)$.

\section{Conclusion}

In conclusion, the YDP on CLP was developed and applied with a group of students at a middle school, providing a tool to disseminate information regarding CLP. An increase in the knowledge regarding the content was observed after participation in the YDP, suggesting that this educational strategy may be an effective tool to multiply knowledge and to optimize health promotion and advocacy.

\section{References}

1 Cash AC. Orthodontic treatment in the management of cleft lip and palate. Front Oral Biol 2012;16:111-123

2 Pegelow M, Alqadi N, Karsten AL. The prevalence of various dental characteristics in the primary and mixed dentition in patients born with non-syndromic unilateral cleft lip with or without cleft palate. Eur J Orthod 2012;34(5):561-570

3 Pereira ACMM, Mota SAS. Análise da influência do estigma físico nas relações interpessoais em indivíduos com malformações crânio-faciais: fissura lábio-palatina. Mimesis 1997;18(1): 143-154

4 Gertel MCR, Maia SM. Speech therapist and school-considerations about the inclusive educational system: case report. Rev CEFAC 2011;13(5):954-961

5 Wen CL, Silveira PSP, Azevedo RS, Böhm GM. Internet discussion lists as an educational tool. J Telemed Telecare 2000;6(5):302-304

6 Haney M, Silvestri S, Van Dillen C, Ralls G, Cohen E, Papa L. A comparison of tele-education versus conventional lectures in wound care knowledge and skill acquisition. J Telemed Telecare 2012;18(2):79-81
7 Soirefmann M, Boza JC, Comparin C, Cestari TF, Wen CL. Cybertutor: a teaching tool in dermatology. An Bras Dermatol 2010;85(3): 400-402

8 Silva ASC, Rizzante FAP, Picolini MM, et al. Bauru School of Dentistry Tele-Health League: an educational strategy applied to research, teaching and extension among applications in telehealth. J Appl Oral Sci 2011;19(6):599-603

9 Blasca WQ Maximino LP, Galdino DG, Campos K, Picolini MM. Novas tecnologias educacionais no ensino da audiologia. Rev CEFAC 2010;12(6):1017-1024

10 Macea DD, Rondon S, Chaar LJ, Wen CL. Public health education for young students aided by technology. J Telemed Telecare 2009; 15(3):159

11 Corrêa CC, Martins A, Pardo-Fanton CS, et al. Ações de teleducação interativa em saúde vocal baseadas na dinâmica do projeto jovem doutor. Distúrb Comum 2012;24(3):359-368

12 Vieira MMRM, Berretin-Felix G, Brasolotto AG. The Virtual Man Project's CD-ROM “Voice Assessment: Speech-Language Pathology and Audiology \& Medicine," Vol. 1. J Appl Oral Sci 2009;17 (Suppl):43-49

13 Picolini MM, Blasca WQ Richieri-Costa A, Maximino LP. The development of a virtual learning environment in genetic syndromes. Rev CEFAC 2013;15(2):382-390

14 Chao LW, Silveira PSP, Böhm GM. Telemedicine and education in Brazil. J Telemed Telecare 1999;5(2):137-138

15 Freitas LAM, Barroso HFB, Rodrigues HG, Aversi-Ferreira TA. Construction of embryonic models with recycled material for didactic using. Biosci J 2008;24(1):91-97

16 Vieira CM, Denari FE. Informative program about mental retardation and inclusion: adjustment in social attitudes of children without disabilities. ABPEE 2012;18(2):265-282

17 Spinard ACP, Blasca WQ De-Vitto LM. Genética e Fonoaudiologia: aprendizado baseado na teleducação. Pro Fono 2008;20:42-44 